\title{
PROGRAM KONVERSI CITRA NOTASI BALOK MENJADI NOTASI ANGKA
}

\author{
Hendy Gunawan ${ }^{1}$, Janson Hendryli $^{2}$, Dyah Erny Herwindiati ${ }^{3}$ \\ Program Studi Teknik Informatika, Fakultas Teknologi Informasi, Universitas Tarumanagara, \\ Jln. Letjen S. Parman No. 1, Jakarta, 11440, Indonesia

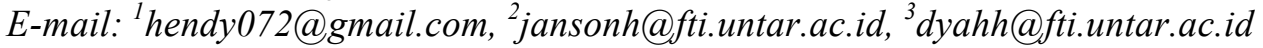

\begin{abstract}
Abstrak
Program Konversi Citra Notasi Balok Menjadi Notasi Angka adalah sebuah sistem Character Recognition yang menerima input berupa citra partitur notasi balok dan menghasilkan output berupa file DOCX berisi notasi angka dari citra input. Notasi balok adalah cara penulisan karya musik yang memiliki nilai notasi, nilai ritmus, dan ditulis dengan garis paranada. Sistem Konversi Citra Notasi Balok Menjadi Notasi Angka terdiri dari empat proses utama yaitu preprocessing citra input, segmentasi baris garis paranada, segmentasi karakter notasi, dan pengenalan dengan template matching. Preprocessing citra input terdiri dari proses grayscale, dan thresholding. Template matching digunakan untuk mencari karakter notasi balok yang didapatkan dengan membandingkan citra tersebut dengan template-template yang ada. Untuk dapat menggunakan metode template matching, ukuran citra template dan ukuran akhir segmentasi disamakan. Sistem ini memiliki tingkat keberhasilan pada segmentasi karakter sebesar 100\% dan tingkat keberhasilan pada pengenalan karakter dengan template matching sebesar $38,4843 \%$.
\end{abstract}

Kata kunci-Notasi Angka, Notasi Balok, Pengenalan Karakter, Segmentasi Karakter, Template Matching.

\begin{abstract}
The Image Conversion Program of Music Notation being Numeric Notation is a character recognition system that accepts input in form of music notation image that produces output of a DOCX file containing the numeric notation from the input image. Music notation has notation value, ritmic value and written with a music stave. The system consist four main process: preprocessing (grayscale and thresholding), notation line segmentation, notation character segmentation and template matching. Template matching is used to recognize the music notation that obtained after segmentation. The recognition process obtained by comparing the image with the template image that has been inputed before to the database. This system has $100 \%$ success rate on segmentation of the character and success rate $38,4843 \%$ on the character recognition with template matching.
\end{abstract}

Keywords-Character Recognition, Character Segmentation, Music Notation, Numeric Music Notation, Template Matching. 


\section{PENDAHULUAN}

Musik secara umum dikenal sebagai media untuk hiburan atau meramaikan suasana sebuah acara, saat ini digunakan sebagai media untuk memperbaiki mood dan meningkatkan konsentrasi. Musik yang sudah berkembang sedemikian rupa saat ini, menjadikan edukasi musik salah satu bidang yang sangat diminati untuk dipelajari, edukasi musik yang baik tidak terlepas dari peranan komposisi-komposisi atau panduan bermain musik yang sudah ada dan menjadi acuan dalam belajar musik. Komposisi musik dalam bentuk tercetak atau tertulis disebut partitur.

Penulisan notasi musik dengan mengunakan notasi balok yang menjadi standar penulisan partitur musik sulit dibaca bagi orang yang tidak memiliki pendidikan musik formal di sekolah musik atau sejenisnya. Notasi angka yang juga menjadi salah satu cara penulisan notasi musik lebih mudah untuk dipahami karena banyak diajarkan di sekolah-sekolah formal dalam pelajaran kesenian.

Tujuan pembuatan program ini adalah untuk mengkonversi citra notasi balok menjadi notasi angka agar dapat lebih mudah dimengerti oleh orang yang tidak bisa membaca notasi balok, serta membantu dalam pengajaran musik bagi orang yang baru belajar musik namun tidak mampu membaca notasi balok. Konversi citra ini melalui proses pre-processing yaitu grayscale dan thresholding, segmentasi dengan projection profile-based histogram dan pengenalan karakter menggunakan template matching.

\section{METODE PENELITIAN}

\subsection{Greyscale}

Proses greyscale digunakan untuk menyederhanakan model citra. Citra berwarna terdiri dari tiga lapisan matriks yaitu lapisan matriks Red (R), Green (G), dan Blue (B), masing-masing nilai $\mathrm{R}, \mathrm{G}$, dan $\mathrm{B}$ akan diubah menjadi nilai grayscale dengan nilai $\mathrm{S}$ dengan mengambil ratarata dari nilai R, G, dan B sehingga dapat dituliskan pada persamaan berikut [1]:

$$
\text { Grayscale }(S)=\frac{R+G+B}{3}
$$

Keterangan :

$\mathrm{S}=$ nilai piksel grayscale

$\mathrm{R}=$ nilai piksel red (merah)

$\mathrm{G}=$ nilai piksel green (hijau)

$\mathrm{B}=$ nilai piksel blue (biru)

\subsection{Thresholding}

Thresholding adalah suatu proses pengubahan citra menjadi citra biner. Proses thresholding akan menghasilkan citra yang hanya memiliki dua nilai piksel, yaitu hitam dan putih yang disebut citra biner. Proses pengambangan citra grayscale untuk menghasilkan citra biner secara umum adalah sebagai berikut [2]:

$$
G(x, y)=\left\{\begin{array}{l}
1 \text { if } f(x, y) \geq T \\
0 \text { if } f(x, y) \leq T
\end{array}\right.
$$

Keterangan :

$\mathrm{G}(\mathrm{x}, \mathrm{y})=$ nilai citra biner

$\mathrm{f}(\mathrm{x}, \mathrm{y})=$ nilai piksel yang akan dibinerkan

$\mathrm{T}=$ nilai ambang (threshold) 


\subsection{Segmentasi}

Segmentasi citra merupakan suatu proses yang membagi citra ke dalam beberapa bagian, yaitu bagian yang diperlukan dan bagian yang tidak diperlukan oleh sistem [3]. Untuk segmentasi baris notasi balok dan not balok digunakan metode projection profile-based histogram dengan menjadikan objek ke dalam bentuk garis-garis histogram vertikal dan horizontal. Metode ini berdasarkan pada penggunaan profil histogram yang telah tercipta dan diproporsikan oleh suatu citra. Profil dari proyeksi merupakan sebuah struktur data yang digunakan untuk menyimpan sejumlah piksel hitam yang merupakan objek ketika suatu citra diproyeksikan melalui sumbu $\mathrm{x}$ maupun sumbu $\mathrm{y}$. Perhitungan dilakukan dengan cara menghitung jumlah piksel hitam pada suatu citra secara mendatar (horisontal) dan juga secara menurun (vertikal) [4].

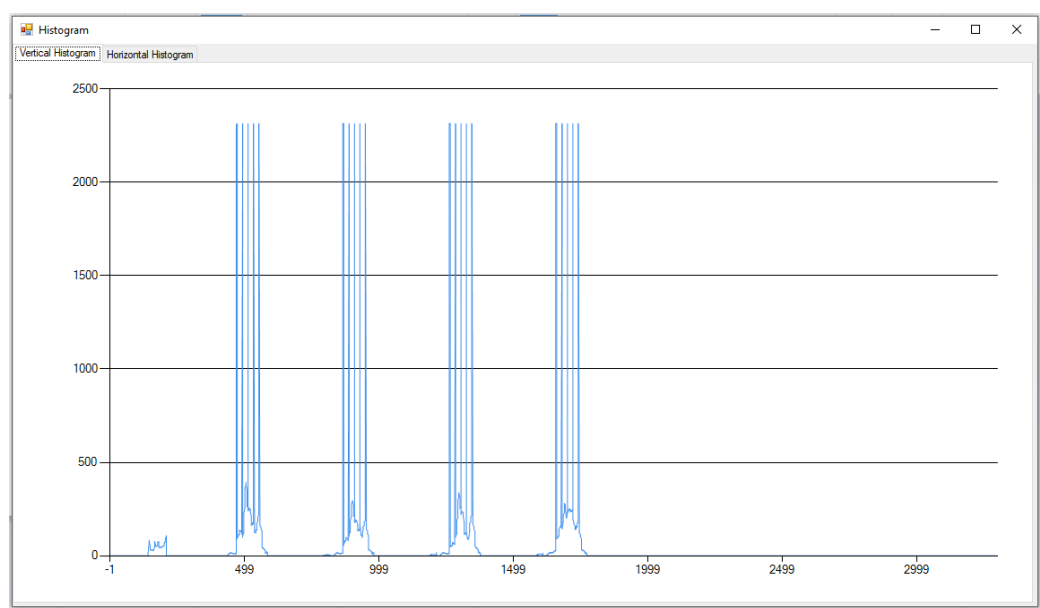

Gambar 1 Contoh Histogram Horisontal Partitur Yang Digunakan Untuk Segmentasi Baris Paranada

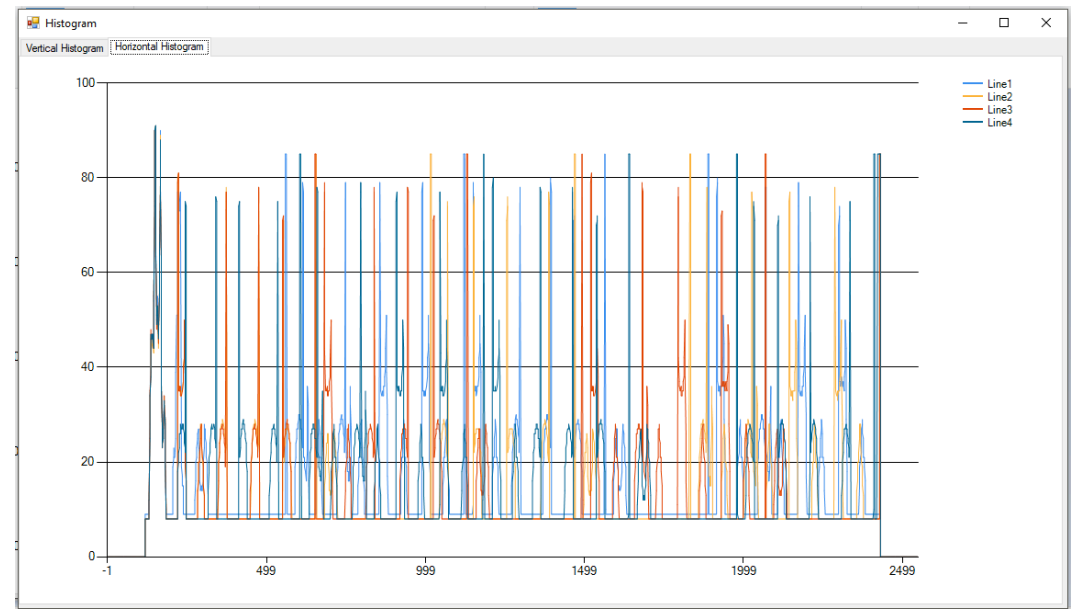

Gambar 2 Contoh Histogram Vertikal Partitur Yang Digunakan Untuk Segmentasi Karakter Not Balok

\subsection{Template Matching}

Template matching adalah salah satu teknik pengenalan citra. Template ditempatkan pada pusat bagian citra yang akan dibandingkan dan dihitung seberapa banyak titik yang paling sesuai dengan template. Dalam pengolahan citra, metode ini berfungsi untuk mencocokan tiaptiap bagian dari suatu citra dengan citra yang menjadi template atau acuan. Teknik ini biasanya digunakan dalam bidang industry sebagai quality control [5].

Template matching dapat dibagi antara empat pendekatan yaitu: 
1. Feature-based approach

Pendekatan berbasis fitur digunakan ketika terdapat dua refrensi dari kerangka gambar atau template memiliki lebih banyak korespondensi sehubungan dengan fitur dan titik kontrol. Fitur yang dimaksud berhubungan dengan kurva, poin, atau permukaan yang harus dicocokan. Subkategori dari pendekatan fitur ini adalah spatial relations, invariant descriptor, pyramids, serta wavelet and relaxation methods.

2. Template-based approach

Untuk template tanpa fitur yang kuat, atau ketika sebagian besar template gambar merupakan gambar yang tetap atau statis, sebuah pendekatan berbasis template mungkin efektif. Pada pendekatan ini diperlukan jumlah sampling citra dengan resolusi pencarian dan template gambar dengan faktor yang sama.

3. Motion-tracking and colission handling

Pada template yang tidak dapat memberikan pencocokan langsung, diterapkan penggunaan eignspaces-template dimana objek yang lebih detail yang sesuai dengan sejumlah kondisi yang berbeda, seperti berbagai perspektif, iluminasi, warna kontras, atau objek yang cocok diterima. Misalnya untuk mencari raut wajah, eigenspaces dapat terdiri dari gambar (template) wajah dalam posisi yang berbeda pada kamera, kondisi pencahayaan yang berbeda, atau dengan ekspresi yang berbeda.

4. Template-based matching and convolution

Metode dasar template matching yang menggunakan convolution mask (template) yang disesuaikan dengan fitur tertentu dari template matching yang ingin kita deteksi. Teknik ini dapat dengan mudah dilakukan pada gambar greyscale. Metode ini biasanya digunakan dengan cara terlebih dahulu memilih sebuah bagian dari gambar pencarian untuk digunakan sebagai template.

\section{HASIL DAN PEMBAHASAN}

Hasil percobaan yang dilakukan terhadap proses-proses yang ada pada program menggunakan 30 citra partitur notasi balok yang ditulis menggunakan program MuseScore $2.1{ }^{\circledR}$ menghasilkan rata-rata $100 \%$ untuk proses segmentasi yang dapat dilihat pada tabel 1 .

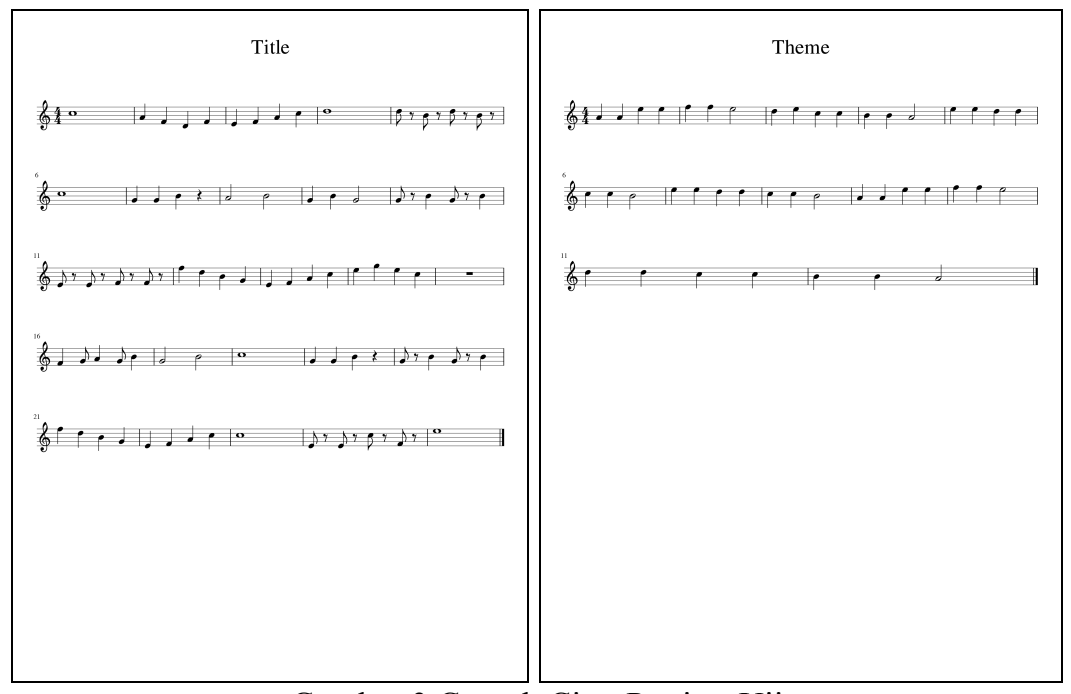

Gambar 3 Contoh Citra Partitur Uji 
Tabel 1 Hasil Pengujian Segmentasi Karakter

\begin{tabular}{|c|c|c|c|}
\hline $\begin{array}{c}\text { Nama citra } \\
\text { uji }\end{array}$ & $\begin{array}{c}\text { Jumlah karakter } \\
\text { Citra Uji } \\
\end{array}$ & $\begin{array}{l}\text { Jumlah karakter yang } \\
\text { berhasil di segmentasi }\end{array}$ & $\begin{array}{c}\text { Persentase keberhasilan } \\
\text { segmentasi }\end{array}$ \\
\hline Citra Uji 1 & 23 karakter & 23 karakter & $100 \%$ \\
\hline Citra Uji 2 & 12 karakter & 12 karakter & $100 \%$ \\
\hline Citra Uji 3 & 12 karakter & 12 karakter & $100 \%$ \\
\hline Citra Uji 4 & 12 karakter & 12 karakter & $100 \%$ \\
\hline Citra Uji 5 & 102 karakter & 102 karakter & $100 \%$ \\
\hline Citra Uji 6 & 116 karakter & 116 karakter & $100 \%$ \\
\hline Citra Uji 7 & 84 karakter & 84 karakter & $100 \%$ \\
\hline Citra Uji 8 & 113 karakter & 113 karakter & $100 \%$ \\
\hline Citra Uji 9 & 126 karakter & 126 karakter & $100 \%$ \\
\hline Citra Uji 10 & 91 karakter & 91 karakter & $100 \%$ \\
\hline Citra Uji 11 & 48 karakter & 48 karakter & $100 \%$ \\
\hline Citra Uji 12 & 73 karakter & 73 karakter & $100 \%$ \\
\hline Citra Uji 13 & 42 karakter & 42 karakter & $100 \%$ \\
\hline Citra Uji 14 & 46 karakter & 46 karakter & $100 \%$ \\
\hline Citra Uji 15 & 49 karakter & 49 karakter & $100 \%$ \\
\hline Citra Uji 16 & 43 karakter & 43 karakter & $100 \%$ \\
\hline Citra Uji 17 & 51 karakter & 51 karakter & $100 \%$ \\
\hline Citra Uji 18 & 39 karakter & 39 karakter & $100 \%$ \\
\hline Citra Uji 19 & 55 karakter & 55 karakter & $100 \%$ \\
\hline Citra Uji 20 & 48 karakter & 48 karakter & $100 \%$ \\
\hline Citra Uji 21 & 39 karakter & 39 karakter & $100 \%$ \\
\hline Citra Uji 22 & 45 karakter & 45 karakter & $100 \%$ \\
\hline Citra Uji 23 & 26 karakter & 26 karakter & $100 \%$ \\
\hline Citra Uji 24 & 35 karakter & 35 karakter & $100 \%$ \\
\hline Citra Uji 25 & 56 karakter & 56 karakter & $100 \%$ \\
\hline Citra Uji 26 & 32 karakter & 32 karakter & $100 \%$ \\
\hline Citra Uji 27 & 55 karakter & 55 karakter & $100 \%$ \\
\hline Citra Uji 28 & 64 karakter & 64 karakter & $100 \%$ \\
\hline Citra Uji 29 & 82 karakter & 82 karakter & $100 \%$ \\
\hline Citra Uji 30 & 70 karakter & 70 karakter & $100 \%$ \\
\hline
\end{tabular}


Computatio: Journal of Computer Science and Information Systems, volume 2, no 2, Oktober 2018

Rata-rata tingkat keberhasilan dari pengenalan karakter dengan template matching dari hasil segmentasi 30 citra partitur notasi balok yaitu 38, 4843\%. Hasil pengujian dapat dilihat pada tabel 2 di bawah ini.

Table 2 Hasil Pengujian Template Matching

\begin{tabular}{|c|c|c|c|}
\hline $\begin{array}{l}\text { Nama citra } \\
\text { uji }\end{array}$ & $\begin{array}{l}\text { Jumlah karakter } \\
\text { citra uji }\end{array}$ & $\begin{array}{l}\text { Jumlah karakter } \\
\text { yang berhasil kenali }\end{array}$ & $\begin{array}{l}\text { Persentase keberhasilan } \\
\text { template matching }\end{array}$ \\
\hline Citra Uji 1 & 23 karakter & 14 karakter & $69,8695 \%$ \\
\hline Citra Uji 2 & 12 karakter & 5 karakter & $41,6666 \%$ \\
\hline Citra Uji 3 & 12 karakter & 4 karakter & $33,3333 \%$ \\
\hline Citra Uji 4 & 12 karakter & 5 karakter & $41,6666 \%$ \\
\hline Citra Uji 5 & 84 karakter & 44 karakter & $52,3809 \%$ \\
\hline Citra Uji 6 & 108 karakter & 48 karakter & $44,4444 \%$ \\
\hline Citra Uji 7 & 84 karakter & 19 karakter & $22,6191 \%$ \\
\hline Citra Uji 8 & 101 karakter & 63 karakter & $62,3762 \%$ \\
\hline Citra Uji 9 & 126 karakter & 33 karakter & $26,1905 \%$ \\
\hline Citra Uji 10 & 129 karakter & 46 karakter & $35,6589 \%$ \\
\hline Citra Uji 11 & 48 karakter & 19 karakter & $39,5833 \%$ \\
\hline Citra Uji 12 & 73 karakter & 29 karakter & $39,7261 \%$ \\
\hline Citra Uji 13 & 42 karakter & 13 karakter & $30,9523 \%$ \\
\hline Citra Uji 14 & 46 karakter & 8 karakter & $17,3913 \%$ \\
\hline Citra Uji 15 & 49 karakter & 34 karakter & $69,3877 \%$ \\
\hline Citra Uji 16 & 43 karakter & 9 karakter & $20,9302 \%$ \\
\hline Citra Uji 17 & 51 karakter & 13 karakter & $25,4901 \%$ \\
\hline Citra Uji 18 & 39 karakter & 16 karakter & $41,0256 \%$ \\
\hline Citra Uji 19 & 55 karakter & 13 karakter & $23,6364 \%$ \\
\hline Citra Uji 20 & 48 karakter & 5 karakter & $10,4166 \%$ \\
\hline Citra Uji 21 & 39 karakter & 16 karakter & $41,0256 \%$ \\
\hline Citra Uji 22 & 45 karakter & 24 karakter & $53,3333 \%$ \\
\hline Citra Uji 23 & 26 karakter & 14 karakter & $53,8462 \%$ \\
\hline Citra Uji 24 & 35 karakter & 15 karakter & $42,8571 \%$ \\
\hline Citra Uji 25 & 56 karakter & 0 karakter & $0 \%$ \\
\hline Citra Uji 26 & 32 karakter & 15 karakter & $46,875 \%$ \\
\hline Citra Uji 27 & 55 karakter & 17 karakter & $30,9091 \%$ \\
\hline Citra Uji 28 & 64 karakter & 31 karakter & $48,4375 \%$ \\
\hline Citra Uji 29 & 82 karakter & 34 karakter & $41,4634 \%$ \\
\hline Citra Uji 29 & 70 karakter & 44 karakter & $62,8571 \%$ \\
\hline Citra Uji 30 & 105 karakter & 67 karakter & $63,8095 \%$ \\
\hline
\end{tabular}


Pada citra uji 25, tingkat keberhasilan pengenalan $0 \%$ disebebkan citra uji 25 notasi balok yang ditulis cenderung berulang-ulang dan notasi yang berulang tersebut tidak terdeteksi dengan baik oleh program.

Berdasarkan hasil pengujian yang telah dilakukan terhadap metode template matching yang digunakan hasil konversi kurang maksimum karena hasil output dari program penulisan partitur MuseScore 2.1 ${ }^{\circledR}$ yang dirancang untuk menghasilkan output dengan ekstensi file XML dan tidak dibuat untuk mengeluarkan output citra membuat ukuran dan posisi piksel berubahubah setiap penulisan partitur notasi balok.

\section{KESIMPULAN}

Berdasarkan percobaan dan pengujian yang telah dilakukan terhadap cropping atau segmentasi dengan projection profil-based histogram dan metode template matching untuk pengenalan karakter, maka dapat disimpulkan bahwa:

1. Cropping atau segmentasi karakter not balok dari tiga pulu citra uji menghasilkan persentase keberhasilan sebesar $100 \%$.

2. Pengenalan hasil segmentasi menggunakan metode template matching menghasilkan persentase keberhasilan sebesar 38,4843\%.

3. Pengenalan yang dilakukan terhadap notasi dengan nilai ketukan half note dan full note sulit dilakukan karena posisi piksel cenderung bergeser.

Saran yang diberikan untuk program ini dan juga penelitian berikutnya adalah:

1. Menambahkan program agar dapat mengkonversi dalam nada dasar lain dan membaca time signature, artikulasi, ornament dan dinamika.

2. Mengembangkan agar program dapat mengkonversi berdasarkan bass clef serta dapat menerima input citra dari hasil scaning menggunakan scanner.

\section{UCAPAN TERIMA KASIH}

Terima kasih saya ucapkan kepada pembimbing penulis dalam pembuatan makalah ini, serta kepada seluruh dosen dan karyawan Fakultas Teknologi Informasi Universitas Tarumanagara yang sudah membantu dalam proses perkuliahan penulis. Terima kasih juga kepada segenap keluarga, teman dan pendahulu saya yang sudah memberikan berbagai bentuk support dalam proses pembuatan makalah ini.

\section{DAFTAR PUSTAKA}

[1] Choras, Ryszard S. Image Processing \& Communications Chalange. London: World Congress of Engineering 2011. 2011.

[2] Sutramiani, Ni Putu; Putra, I Ketut Gede Darma dan Made Sudarma. "Local Adaptive Thresholding Pada Preprocessing Citra Lontar Aksara Bali”, Jurnal Teknologi Elektro, Vol. 14, Nomor 1, 2015.

[3] Munir, Rinaldi, Pengolahan Citra Digital dengan Pendekatan Algoritmik Informatika, Informatika, Bandung, 2004.

[4] Thome, Rodrigues R. dan G. Carlos A. Crusive Character Recognition - a Character Segementation Method Using Projection Profile-based Technique, Journal Nucleo de Computacao Eletronica 2000, Brazil, 2000.

[5] Wardhana, Adhitya Wishnu dan Prayudi Yudi, Penggunaan Metode Template Matching Untuk Identifikasi Kecacatan Pada PCB, Makalah Seminar Nasional Aplikasi Teknologi Informasi 2008 (SNATI 2008), Yogyakarta, 21 Juni 2008. 